\title{
Mycobacterium tuberculosis Shikimate Kinase Inhibitors: Design and Simulation Studies of the Catalytic Turnover $^{\ddagger}$
}

\author{
Beatriz Blanco, ${ }^{\S}$ Verónica Prado, ${ }^{\S}$ Emilio Lence, ${ }^{\S}$ José M. Otero, ${ }^{\dagger}$ Carmela Garcia-Doval, ${ }^{\delta}$ Mark J. \\ van Raaij, ${ }^{\delta}$ Antonio L. Llamas-Saiz, ${ }^{\phi}$ Heather Lamb, ${ }^{\ddagger}$ Alastair R. Hawkins, ${ }^{\ddagger}$ and Concepción Gon- \\ zález-Bello ${ }^{\S *}$
}

${ }^{\S}$ Centro Singular de Investigación en Química Biológica y Materiales Moleculares (CIQUS), Universidad de Santiago de Compostela, 15782 Santiago de Compostela, Spain.

${ }^{\dagger}$ Departamento de Bioquímica y Biología Molecular and Centro Singular de Investigación en Química Biológica y Materiales Moleculares (CIQUS), Universidad de Santiago de Compostela, 15782 Santiago de Compostela, Spain.

${ }^{\delta}$ Departamento de Estructura de Macromoléculas, Centro Nacional de Biotecnología (CSIC), Campus Cantoblanco, 28049 Madrid, Spain.

${ }^{\phi}$ Unidad de Rayos X, RIAIDT, Edificio CACTUS, Universidad de Santiago de Compostela, 15782 Santiago de Compostela, Spain.

${ }^{\ddagger}$ Institute of Cell and Molecular Biosciences, Medical School, University of Newcastle upon Tyne, Newcastle upon Tyne NE2 4HH, UK.

ABSTRACT: Shikimate kinase is an essential enzyme in several pathogenic bacteria and it does not have any counterpart in human cells, thus making it an attractive target for the development of new antibiotics. The key interactions of the substrate and product binding and the enzyme movements that are essential for catalytic turnover of the Mycobacterium tuberculosis shikimate kinase enzyme (Mt-SK) have been investigated by structural and computational studies. Based on these studies several substrate analogs were designed and assayed. The crystal structure of Mt-SK in complex with ADP and one of the most potent inhibitors has been solved at $2.15 \AA$. These studies reveal that the fixation of the diaxial conformation of the $C_{4}$ and $C_{5}$ hydroxyl groups recognized by the enzyme or the replacement of the $C_{3}$ hydroxyl group in the natural substrate by an amino group is a promising strategy for inhibition because it causes a dramatic reduction of the flexibility of the LID and shikimic acid binding domains. Molecular dynamics simulation studies showed that the product is expelled from the active site by three arginines (Arg117, Arg136 and Arg58). This finding represents a previously unknown key role of these conserved residues. These studies highlight the key role of the shikimic acid binding domain in the catalysis and provide guidance for future inhibitor designs.

\section{INTRODUCTION}

According to the World Health Organization (WHO), antibiotic resistance is becoming a public health emergency of unknown proportions. ${ }^{1}$ Despite the recognized need for new antibiotics, the reality is that only two new classes of antibiotics have been brought to the market in the last three decades. ${ }^{2}$ Furthermore, there are few antibacterial agents under development to face the challenge of multidrug resistance. If action is not taken to address these issues, we run the risk of having only a few options to treat bacterial infections. Therefore, there is an urgent need for the discovery of novel drugs and therapies to treat antibiotic-resistant infections and, particularly drugs with new mechanisms of action. A greater understanding of the behavior of antibiotics in biological systems is also required.

One strategy for obtaining new antibiotics is the development of compounds that are capable of interfering with essential bacterial metabolic processes. One exam- ple of such a process is the shikimic acid pathway, in which chorismic acid is synthesized. This compound is the precursor of aromatic amino acids and other metabolites, including folate cofactors, ubiquinone, and vitamins $\mathrm{E}$ and $\mathrm{K} .^{3}$ This biosynthetic route is present in bacteria, fungi, higher plants and certain apicomplexan parasites, ${ }^{4}$ particularly Plasmodium falciparum (which causes malaria), Toxoplasma gondii and Cryptosporidium parvum, but it is absent in mammals. The essential nature of the shikimic acid pathway in certain microorganisms, ${ }^{5}$ combined with its absence in mammals, makes it an attractive target for the development of new antimicrobials and herbicides.

The important features of the shikimic acid pathway have not gone unnoticed by the scientific community and in recent years a great deal of effort has been focused on the development of inhibitors of the enzymes involved in this route. Glyphosate [ $N$-(phosphonomethyl)glycine], the active ingredient in the well-known herbicides Round- 
Up, Zero and Tumbleweed, 'is a good example. This compound is a specific inhibitor of the sixth enzyme of the shikimate pathway [5-enolpyruvylshikimate-3phosphate (EPSP) synthase] ${ }^{6}$ with a $K_{\mathrm{i}}$ of $1 \mu \mathrm{M}$ and it has proven to be active in vitro against malaria. ${ }^{4 a}$ Structural studies have shown that glyphosate occupies the phosphoenol pyruvate binding site in the enzyme, mimicking an intermediate state of the ternary enzyme substrates complex. ${ }^{7}$ Moreover, De María et al. ${ }^{8}$ have shown that the antimicrobial properties of glyphosate are not only due to EPSP inhibition, but also to the high concentrations of shikimic acid and protocatechuate that it causes. The excess of these compounds result in the inhibition of phosphoenolpyruvate carboxylase, an enzyme involved in the metabolism of carbohydrates. In addition, Chen et $a l .{ }^{9}$ showed that the deletion of the aroK gene, which encodes shikimate kinase, the fifth enzyme of the shikimic acid pathway, causes shikimic acid accumulation. These facts attracted our attention because it might be possible to develop new antimicrobials by inhibition of shikimate kinase (SK, EC 2.7.1.71), the enzyme that catalyzes the conversion of shikimic acid (1) into shikimate 3phosphate (2) (Scheme 1). In addition, since this enzyme is essential in Mycobacterium tuberculosis, Helicobacter pylori, Acinetobacter baylyi, Haemophilus influenzae, Francisella novicida and Pseudomonas aeruginosa, would be an attractive target for the development of new drugs against several important bacterial diseases. ${ }^{10}$ In the work described here, we focused on the inhibition of the $M$. tuberculosis enzyme for the development of new chemotherapeutic agents against tuberculosis (TB). This disease is one of the deadliest infectious diseases for humans and it is a primary public health threat. ${ }^{11,12} \mathrm{~TB}$ therapy requires long periods of treatment (around 6 to 24 months) with multiple drugs. This extended treatment leads to poor compliance, a factor that promotes resistance development. Therefore, there is great interest in the discovery and development of alternative TB drugs.

Scheme 1. Enzymatic conversion of shikimic acid (1) to shikimate-3-phosphate (2) catalyzed by the SK enzyme

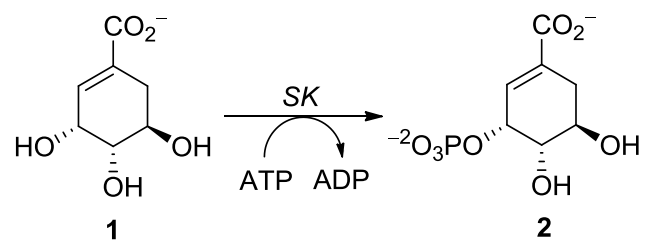

We report here the design, synthesis and biological evaluation of new competitive inhibitors of $M$. tuberculosis shikimate kinase (Mt-SK). Considering that the P-loop, which forms the binding site for ATP and ADP and contains the consensus sequence GXXXXGKT/S (with X being any residue), is rather conserved in many ATP- or GTP-binding proteins, we focused on the design of compounds that bind to the shikimic acid binding site. ${ }^{13}$ The design of the reported inhibitors, compounds 3-9 (Figure 1) was based on structural and molecular dynamics (MD) simulation studies, which helped us to understand the determinants of substrate binding affinity and the key enzyme movements that are essential for catalytic turnover. These computational studies also allowed us to identify a previously unknown key role of conserved residues Arg117, $\operatorname{Arg}_{5} 8$ and $\operatorname{Arg}_{13} 6$ in the release of shikimate-3phosphate (2) from the active site, and provided a detailed knowledge of this process. The crystal structure of $M t$-SK in complex with ADP and one of the most potent inhibitors is described along with the results of inhibition studies.

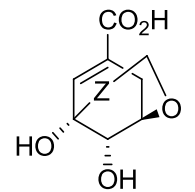

$3 \mathrm{Z}=(\mathrm{Z}) \mathrm{CH}=\mathrm{CH}$ $4 \mathrm{Z}=\mathrm{CH}_{2} \mathrm{CH}_{2}$

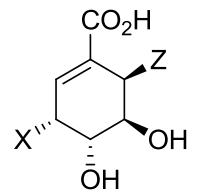

$$
6 \mathrm{X}=\mathrm{Z}=\mathrm{OH}
$$$$
7 \mathrm{X}=\mathrm{NH}_{2} ; \mathrm{Z}=\mathrm{H}
$$
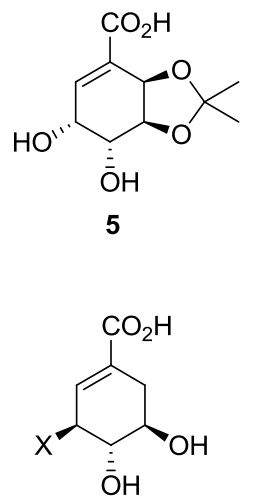

$8 \mathrm{X}=\mathrm{OH}$ $9 \mathrm{X}=\mathrm{NH}_{2}$
Figure 1. Shikimic acid analogs

\section{RESULTS AND DISCUSSION}

\section{Molecular Dynamics Simulation Studies: Substrate Binding and Product Release}

$M t$-SK enzyme has three domains (Figure 2): ${ }^{14}$ (1) the CORE domain containing a five stranded parallel $\beta$ sheets and the P-loop (residues $9^{-17}$ ), which forms the binding site for ATP and ADP; (2) the LID domain (residues 112-124), which closes over the active site and has residues that are essential for the binding of ATP; and (3) the substrate binding (SB) domain (residues 33-61, $\alpha$ helices $\alpha_{2}, \alpha_{3}$ and $\alpha_{4}$ ), which is responsible for the recognition and binding of shikimic acid (1). Circular dichroism, ${ }^{13}$ fluorescence ${ }^{14}$ and structural ${ }^{15,16}$ studies suggested that ATP first binds to the enzyme and induces a large movement of the LID domain over the active site. After this, shikimic acid (1) binds to the active site and the LID domain closes over the active site bringing Argno and Arg117 into the ATP and SB domains, respectively. ${ }^{16}$ The shikimic acid binds to the active site through direct and indirect contacts, mainly via the side chains of Arg136 and Asp34 and a water network. The phosphoryl transfer has been proposed to proceed through a direct in-line associative mechanism involving Asp34 as a general base to deprotonate the $C_{3}$ hydroxyl group in 1 for nucleophilic attack. ${ }^{16}$ The resulting pentacovalent intermediate would then be stabilized by electrostatic interactions with the side chains of Lys15 and Arg117 and $\mathrm{Mg}^{2+}$, which may neutralize the developing negative charge.

MD simulations were carried out in order to analyze the key interactions that control the unusual conformation required by shikimic acid (1) in the $M t$-SK active site and 
the enzyme movements that are essential for catalytic turnover. To this end, the enzyme complexes of substrates $(M t$-SK/ATP/1) and products $(M t$-SK/ADP/2) were subjected to $10 \mathrm{~ns}$ of simulation to analyze the dynamic behavior of substrate and product interactions, respectively.

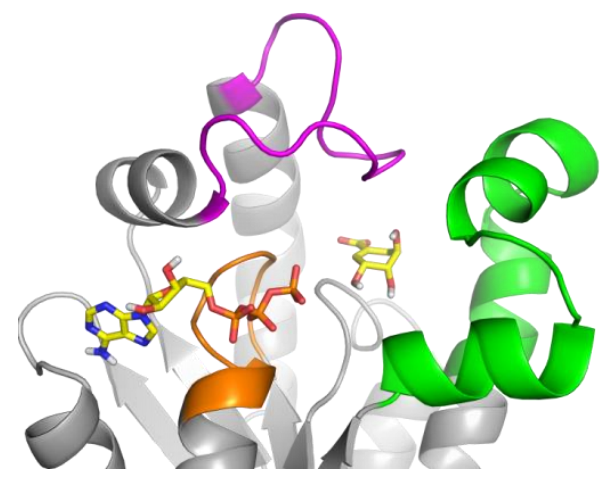

Figure 2. Representation of the overall structure of $M t-S K$ highlighting the three domains: CORE (orange), LID (magenta) and SB (green). ${ }^{17}$

The Michaelis complex. The dynamic behavior of the MtSK/ATP/1 ternary complex was studied first. This complex was generated using the enzyme geometries found in the crystal structure of $M t$-SK in complex with ADP and shikimic acid (1) (PDB code $2 \mathrm{IYQ}^{16}$ ) and after manual replacement of ADP by ATP. ${ }^{18}$ The results showed that there are small movements in the relative positions of both substrates in the active site during the simulation (10 ns) (Figure 3). Thus, the distance between the $\gamma$ phosphate of ATP and oxygen of the $C_{3}$ hydroxyl group of 1 varies between 4.4 and $6.4 \AA$, mainly due to a to-and-fro movement of the SB domain (see supporting information). This movement is essential for catalysis because it is how the enzyme approximates both substrates together for the bimolecular reaction. Small movements were also observed in the LID domain, but not in the relative position of ATP and Arg117, which is essential for the binding of ATP, and in the $\beta$-sheet $\beta_{3}$, where the conserved Asp32 residue is located. The latter is consequence of the to-and-fro movement of the SB domain. It has been suggested that the hydrogen bond interaction between the Asp32 and Ser16 side chains, which is located close to the $\beta$-phosphate of ATP, may contribute to the approximation of both substrates during the phosphoryl transfer reaction. ${ }^{16}$

It is noteworthy that, when both substrates are close together, the guanidinium group of $\operatorname{Arg} 117$ ( $\mathrm{NH} 2$ and NE) forms two hydrogen bonds with the $\gamma$-phosphate of ATP and water molecules are not observed between the two substrates. This finding suggests that this residue might also act as a Lewis acid during the enzymatic catalysis, by activating and positioning the phosphoryl group of ATP for nucleophilic attack by the $C_{3}$ hydroxyl group and may also stabilize the phosphoryl oxygen atoms in the transition state.

As has been suggested, the substrate remains strongly bound to the active site by a salt bridge with the guanidi- um group of Arg136 and by hydrogen bonding between the side chain of the conserved Asp34 residue and the $\mathrm{C}_{4}$ hydroxyl group. These interactions do not change significantly during the simulation (10 ns), suggesting that the substrate is strongly anchored to the enzyme active site through the interactions. By contrast, the hydrogen bonding between the hydroxyl group at $\mathrm{C}_{3}$ and the Asp34 side chain, which is observed in numerous crystal structures, ${ }^{14,16,19}$ is easily lost during the simulation, particularly when both substrates are very close (see supporting information). Moreover, the $C_{3}$ hydroxyl group is arranged in an equatorial disposition in order to proceed with the phosphoryl transfer reaction by forcing the axial dispositions of $\mathrm{C}_{4}$ and $\mathrm{C}_{5}$ hydroxyl groups. The latter arrangement is wonderfully achieved by hydrogen-bonding interactions with the conserved residues Asp34 and Gly8o and with three water molecules. Specifically, the $C_{4}$ hydroxyl group is fixed in an axial arrangement by hydrogen bonding with the side chain of the conserved Asp34 and with a structural water molecule (WAT1), which does not exchange with the solvent throughout the whole dynamic process (see supporting information). WAT1 is anchored through a set of hydrogen-bonding interactions with the side chains of the conserved amino acids Glu61 and $\operatorname{Arg}_{5} 8$ and the main-chain amide of the conserved residue Gly81 (Figure 3a). Asp34 and Glu61 are always bridged by an exchangeable water molecule, probably to avoid repulsion between these two residues.

This exquisite control of the axial position of the $\mathrm{C}_{4}$ hydroxyl group with one water molecule, the position of which is frozen by the conserved residues Glu61, Arg 58 and Gly8o, is also achieved for the apolar pocket generated by the conserved Phe 49 and Phe57 residues located in $\alpha$-helices $\alpha_{3}$ and $\alpha_{4}$, which isolates this important recognition part of the enzyme from the solvent. On the other hand, the axial disposition of the $C_{5}$ hydroxyl group is fixed by two water molecules that are exchangeable with the solvent (Figure 3 and see supporting information). Both water molecules create a water bridge between the $\mathrm{C}_{1}$ carboxylate group and the $\mathrm{C}_{5}$ hydroxyl group that freeze this conformation. The water molecule closest to the $\mathrm{C}_{5}$ hydroxyl group interacts with the $\mathrm{NH}$ main chain of Leung located in the LID domain. Analysis of the amino acid sequence in various SK (see supporting information) reveals that these water molecules are always embedded in an apolar region, specifically Pro11, Leu119 and Leu132 for Mt-SK, which appears to contribute greatly to their arrangement. Together with Arg117, this contributes to close the active site tightly. By forcing the axial disposition of the $\mathrm{C}_{4}$ and $\mathrm{C}_{5}$ hydroxyl groups, the enzyme controls the equatorial disposition of the $C_{3}$ hydroxyl group and allows its selective phosphoryl-transfer reaction. The hydrogen bonding interaction with the $\mathrm{NH}$ main chain amide of Gly8o, which remains stable during the simulation, allows the appropriate orientation of the oxygen lone pair of the $C_{3}$ hydroxyl group for the phosphoryl-transfer reaction. 

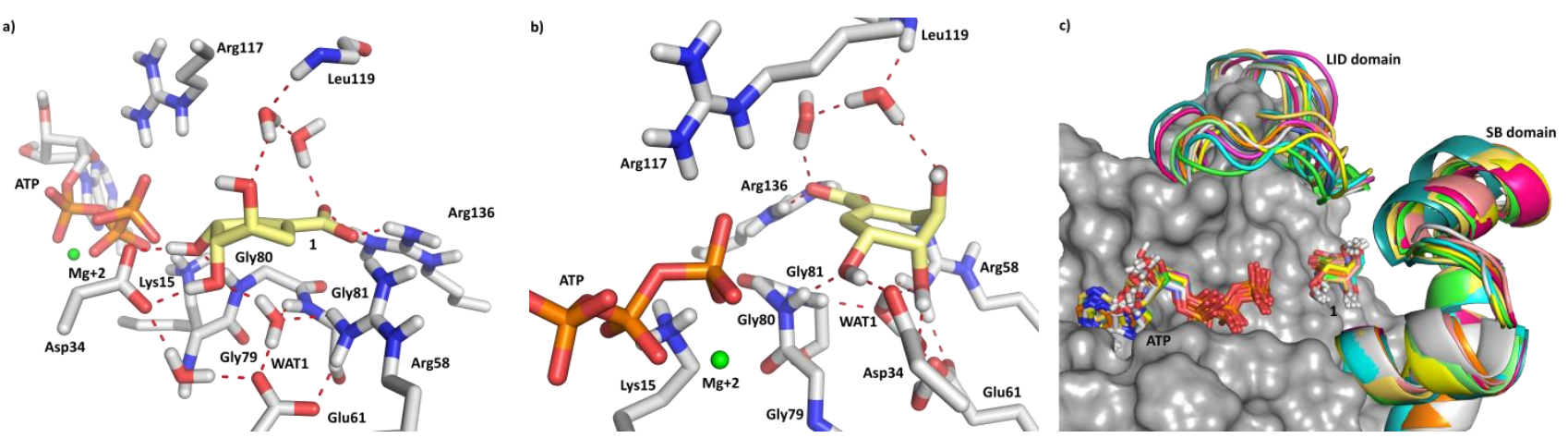

Figure 3. Michaelis complex: a) and b) two views of the relevant binding interactions of shikimic acid (1) in the active site of Mt-SK; c) comparison of the several snapshots of the LID and SB domains and the position of both substrates (ATP, $\mathbf{1})$ of $M t$-SK/ATP/1 complex during 10 ns of MD simulations. Note that significant movements of these domains are not observed and that they remain closed during the simulation. Relevant side chain residues are shown and labeled.
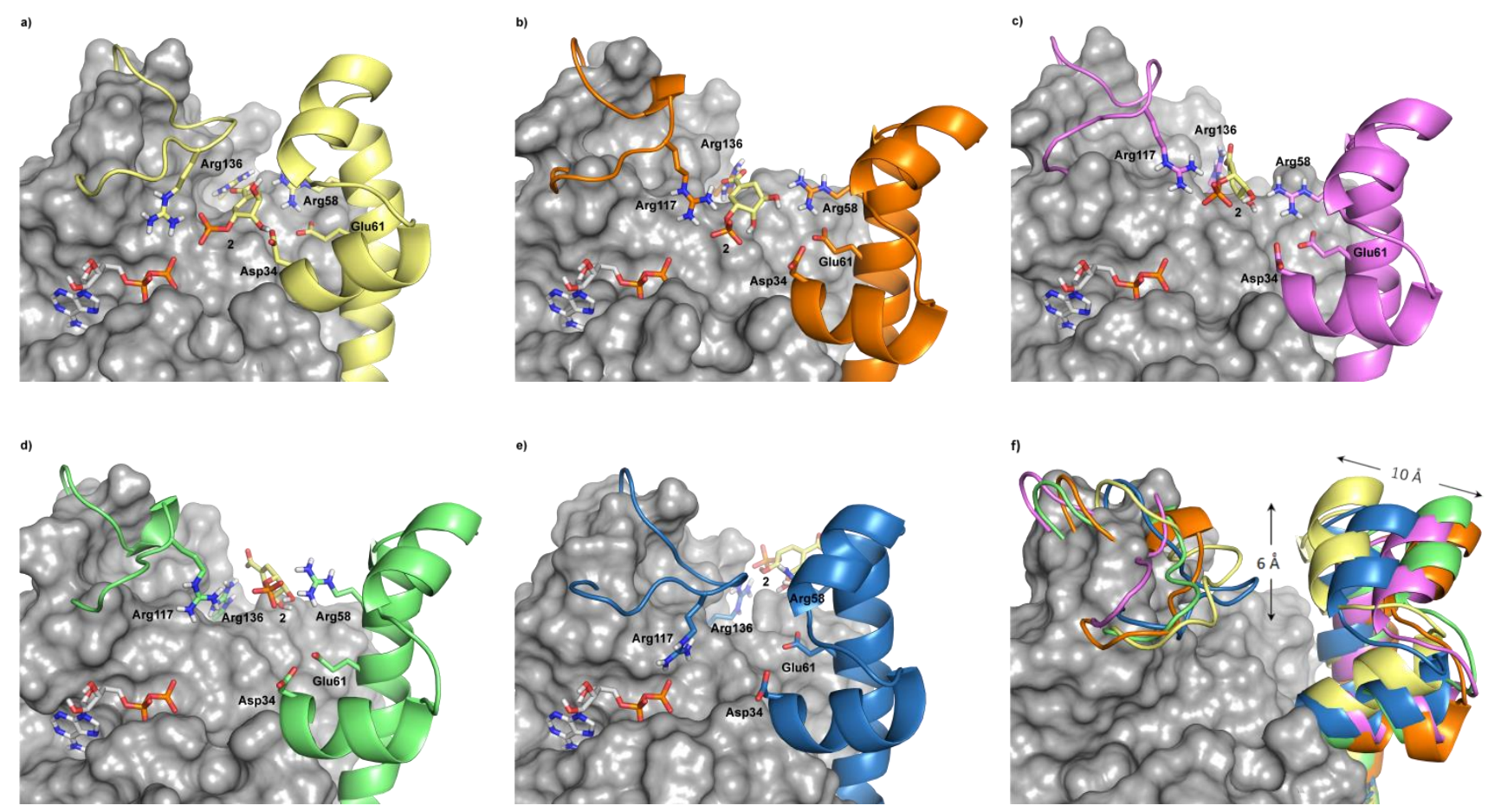

Figure 4. Snapshots of shikimate-3-phosphate (2) (yellow) release from the active site of Mt-SK obtained by MD simulations: (a) after 0.02 ns (yellow); (b) after 0.08 ns (orange); (c) after 0.16 ns (magenta); (d) 2.4 ns (green); (e) after 10 ns (blue); (f) superposition of a-e. Note the large conformational changes of the LID and the $\alpha$-helices $\alpha_{3}$ and $\alpha_{2}$ of the SB binding domains during product release. Significant changes were not observed in the ADP binding site. Relevant side chain residues are shown and labeled.

Enzyme products complex. In order to understand the structural changes responsible for triggering the release of the product from the active site, the dynamic behavior of the $M t$-SK/ADP/2 ternary complex was studied. The results showed that the Asp34 side chain moves away from the $C_{3}$ phosphate group in $\mathbf{2}$ as soon as the dynamic simulation starts ( $20 \mathrm{ps})$, probably due to the electrostatic repulsion caused by the phosphate group, which is now close (Figure 4). More importantly, the Arg117 sidechain located of the LID domain progressively moves toward the $\mathrm{C}_{3}$ phosphate group in 2 ( $\left.\sim 0.8 \mathrm{~ns}\right)$. This strong salt-bridge interaction between the phosphate group in 2 and the guanidinium group of Arg117 triggers the release of the product from the active site. Thus, by pulling on the phosphate group in 2, Argir7 causes the breakage of the favorable interactions of the product with the active site residues, particularly the salt-bridge interaction between the $\mathrm{C}_{1}$ carboxylate group and the guanidinium group of Arg136.

As a result, a significant conformational change in the product and a large movement of the SB domain takes place (up to $10 \AA$ for $\alpha$-helix $\alpha_{3}$ ). Thus, as the product 
loses the key interactions that control the aforementioned kinetic conformation required for catalysis, which is favored by the large movement of the SB domain, it quickly undergoes a $\sim 45^{\circ}$ turn and a conformational change to its thermodynamically favorable conformation, i.e. with the $\mathrm{C}_{4}$ and $\mathrm{C}_{5}$ hydroxyl groups located in a pseudo-equatorial disposition. As the product moves away from the Arg117 residue, the $\operatorname{Arg}_{5} 8$ and Arg136 residues become responsible for expelling the product from the active site. With the product on the way out of the active site, the SB domain recovers its position but it is not such closed form as after substrate binding ( $\sim 2 \AA$ away). During product release, the LID domain also undergoes large movements to allow the Arg117 and Arg136 side chains to be displaced by up to $6 \AA$ in order to expel the product from the active site. Moreover, it is noted that the hydrogen bond that enzyme uses to bring together the SB and nucleotide domains is rapidly broken during the simulation and the Asp32 side chain only interacts now with the $\mathrm{NH}$ main-chains of Asp34 and Val35, which are located in the SB domain.

Taken together, our MD simulation studies highlight that there are four key structural factors required for the catalysis: (1) the $C_{4} / C_{5}$ diaxial conformation of shikimic acid (1); (2) a closed form of the LID domain to allow activation of the $\gamma$-phosphate of ATP and stabilization of the transition state by the guanidinium group of the Argir7 side chain; (3) a closed form of the SB domain in order to bring the substrates together for the phosphoryltransfer reaction and to isolate the substrate within an apolar cavity; (4) a flexible LID and SB domain for product release. On the basis of this knowledge, we decided to study the possible inhibition of the SK enzyme by compounds capable of disturbing these key structural factors and impeding essential enzyme movements. For this purpose, we studied the biological activity of compounds 3-9 (Figure 1), which were designed to fix the required diaxial conformation, to promote electrostatic interactions with the conserved Asp34 side chain and/or $\gamma$ phosphate group of ATP and/or to reduce the flexibility of the SB and LID domains. Moreover, the specificity of the reaction was studied with 3-epi-shikimic acid (8).

\section{Synthesis of Compounds 3-4}

The synthesis of conformationally restricted shikimic acid derivatives $3-4$ involved the formation of the ether bridge by ring-closing metathesis of allyl vinyl derivative 15 and implies the incorporation of the vinyl moiety in $\mathbf{1 5}$ by 1,2-nucleophilic addition of previously reported enone $10{ }^{20}$ which is prepared in two steps from (-)-shikimic acid (1) (Scheme 2 and supporting information). Following our synthetic strategy, the synthesis of allyl vinyl derivative $\mathbf{1 5}$ was first attempted by nucleophilic addition of vinyl magnesium bromide to enone 10 and subsequent formation of the acetonide 14. Vinyl derivative $\mathbf{1 1}$ was diastereoselectively obtained in $72 \%$ yield. The regioselectivity of the reaction was confirmed by NOE experiments. Inversion of the signal of $\mathrm{H} 6$ led to enhancement of the signal for the $\mathrm{H}_{1}{ }^{\prime}$ vinyl group (3.1\%). However, the conversion of vinyl derivative $\mathbf{1 1}$ to the protected alkene
14 was proved difficult because, under standard mild acidic conditions, compound 11 easily undergoes a 1,3transposition to give allyl alcohol 12.

\section{Scheme $2^{a}$}

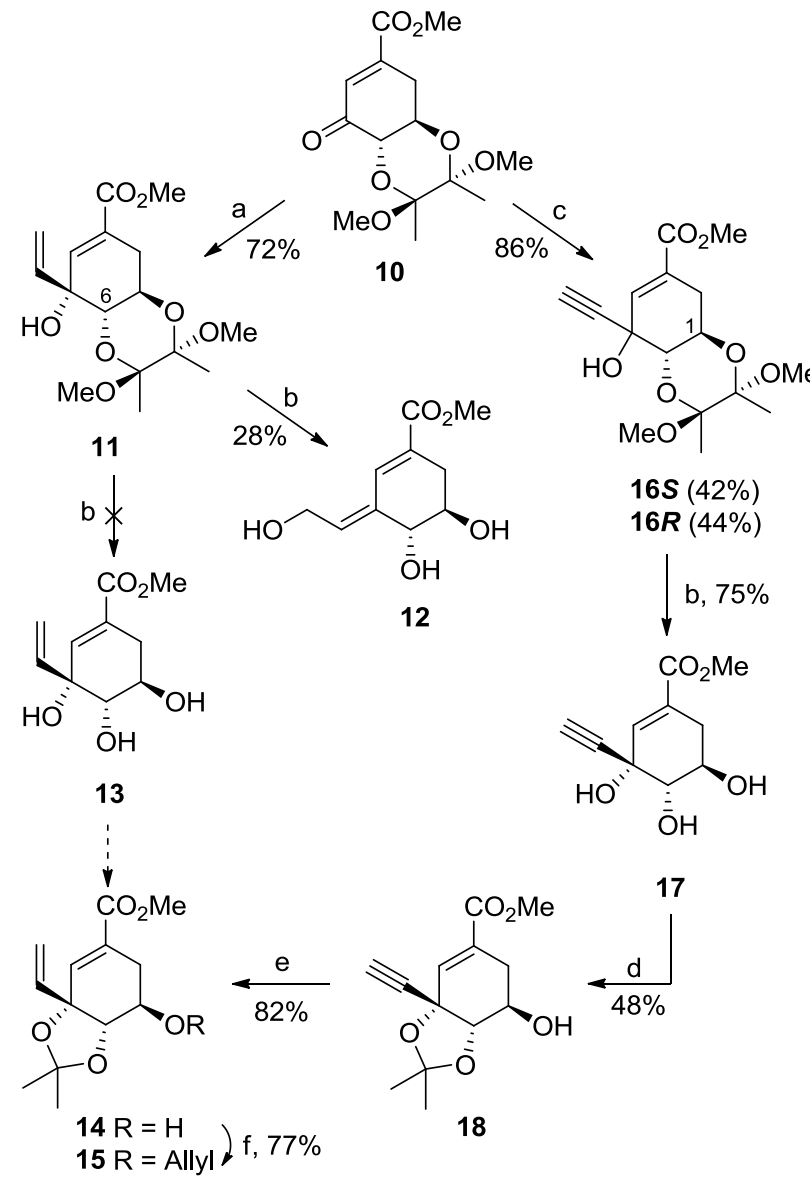

${ }^{a}$ Reagents and conditions: (a) $\mathrm{H}_{2} \mathrm{C}=\mathrm{CHMgBr}$, THF, $-78^{\circ} \mathrm{C}$ to RT. (b) TFA $/ \mathrm{H}_{2} \mathrm{O}$ (20:1), o ${ }^{\circ} \mathrm{C}$. (c) $\mathrm{HC} \equiv \mathrm{CMgBr}, \mathrm{THF},-78$ ${ }^{\circ} \mathrm{C}$ to RT. (d) $\mathrm{C}(\mathrm{Me})_{2}(\mathrm{OMe})_{2}$, acetone, CSA (cat), $\Delta$. (e) $\mathrm{H}_{2}$, Lindar catalyst (cat), EtOH. (f) AllylOCO${ }_{2} \mathrm{Me}, \mathrm{Pd}_{2}\left(\mathrm{dba}_{3}\right.$ (cat), dppb, THF, $\Delta$.

Reasoning that this reaction could be avoided by using the corresponding alkyne derivative, the synthesis of vinyl allyl 15 via alkyne 16 was carried out as shown in Scheme 2. Treatment of enone 10 with ethynyl magnesium bromide at $-78{ }^{\circ} \mathrm{C}$ afforded a chromatographically separable mixture of the two hydroxyl alkynes 16, the stereochemistry of which was confirmed by the NOE experiments. Thus, inversion of the signal of the axial $\mathrm{H}_{1}$ in $16 S$ led to enhancement of the signal for $\mathrm{OH}$ group (1.3\%). Deprotection of $\mathbf{1 6 S}$ with aqueous trifluoroacetic acid followed by cis-1,2-diol protection of the resulting triol 17 afforded acetonide 18. Catalytic hydrogenation of alkyne 18 using Lindar catalyst gave the desired alkene $\mathbf{1 4}$ in $82 \%$ yield. Finally, allylation of $\mathbf{1 4}$ was achieved by treatment with allyl methyl carbonate and a catalytic amount of $\mathrm{Pd}_{2}(\mathrm{dba})_{2} / \mathrm{dppb}$ to give allyl vinyl derivative 15 in $77 \%$ yield.

Ring-closing metathesis of allyl vinyl derivative $\mathbf{1 5}$ in the presence of second-generation Grubbs catalyst in toluene 
at room temperature readily afforded bicyclic derivative 19 in $80 \%$ yield (Scheme 3). Catalytic hydrogenation of alkene 19 using Lindar catalyst in the presence of pyridine gave the desired saturated alkane $\mathbf{2 1}$ in $75 \%$ yield. Finally, bicyclic derivatives 19 and 21 were converted into the desired acids 3 and $\mathbf{4}$, respectively, in two steps. Deprotection of the acetal groups in 19 and 21 with $\mathrm{HCl}$ was followed by basic hydrolysis of the resulting esters 20 and 22, respectively, and subsequent protonation with Amberlite IR-12o $\left(\mathrm{H}^{+}\right)$ion-exchange resin.

\section{Scheme $3^{a}$}

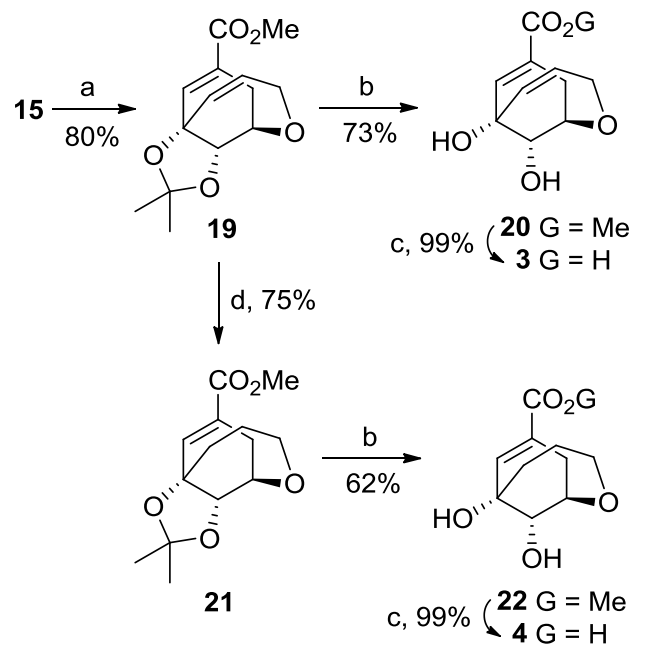

${ }^{a}$ Reagents and conditions: (a) $2^{\text {nd }}$ generation Grubbs' catalyst, PhMe, RT. (b) EtOH, $\mathrm{HCl}(6 \mathrm{M}), 6{ }^{\circ} \mathrm{C}$. (c) 1. $\mathrm{LiOH}$ (aq.), THF, RT. 2. Amberlite IR-12o $\left(\mathrm{H}^{+}\right)$, RT. (d) $\mathrm{H}_{2}$, Lindar catalyst (cat), $\mathrm{Py}, \mathrm{MeOH}$.

\section{Synthesis of Compounds $5^{-9}$}

The synthesis of compounds $\mathbf{5} \mathbf{- 6}$ was achieved from previously reported bromide $23^{21}$ (Scheme 4 and supporting information). TBS protection with TBSOTf and pyridine followed by cross-coupling of the resulting bromide $\mathbf{2 4}$ with $\mathrm{Ni}(\mathrm{CO})\left(\mathrm{PPh}_{3}\right)_{2}^{22}$ in the presence of ethanol afforded the desired ethyl ester 25 in $75 \%$ yield. Deprotection of the TBS groups with TBAF gave the diol $\mathbf{2 6}$, which was converted to the desired (6R)-6-hydroxyshikimic acid $(6)^{23}$ as acid 3 from 19. Diol 26 was converted into the desired acid $\mathbf{5}$ as compound $\mathbf{6}$ from ethyl ester 27. Finally, 3-epishikimic acid (8) and $(3 R)-(7)^{24}$ and (3S)-3aminoshikimic acids (9) were prepared from shikimic acid (1) using slight modifications of previously reported protocols (see supporting information).

\section{Inhibition Activity of Compounds 3-9}

All the reported shikimic acid analogs were assayed against $M t$-SK. Enzyme activity was measured by UV monitoring of the ADP formation by coupling the released of ADP to the oxidation of NADH using pyruvate kinase (PK) and lactate dehydrogenase (LDH) as coupling enzymes. The disappearance of NADH by oxidation to NAD during PK-LDH activity was monitored at $340 \mathrm{~nm}$.
All of the compounds were found not to be substrates for this enzyme, including 3-epi-shikimic acid (8), which illustrates the aforementioned enzyme specificity. These compounds were then assayed in the presence of shikimic acid (1) and ATP for their inhibitory properties against $M t$-SK and they proved to be reversible competitive inhibitors of the enzyme. The inhibition data $\left(K_{\mathrm{i}}\right)$ are summarized in Table 1 . The $K_{\mathrm{i}}$ values were obtained from Dixon plots ( $1 / \mathrm{v} v s[\mathrm{I}])$.

\section{Scheme $4^{a}$}

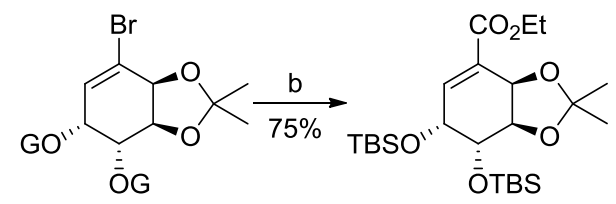

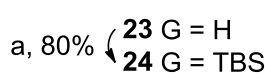

25

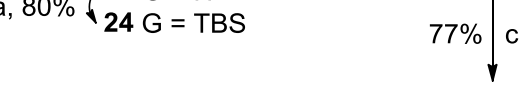<smiles>O=C([O-])C1=C[C@@H](O)C(O)C(O)C1O</smiles>

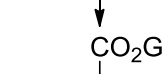<smiles>CC1(C)OC2C=C[C@@H](O)[C@H](O)C2O1</smiles>

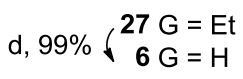
d, $99 \%\left(\begin{array}{rl}26 \mathrm{G} & =\mathrm{Et} \\ \mathbf{5} \mathrm{G} & =\mathrm{H}\end{array}\right.$

${ }^{a}$ Reagents and conditions: (a) TBSOTf, DCM, Py, o ${ }^{\circ} \mathrm{C}$. (b) $\mathrm{Ni}(\mathrm{CO})\left(\mathrm{PPh}_{3}\right)_{2}$, DIPEA, EtOH, $80^{\circ} \mathrm{C}$. (c) TBAF, THF, o ${ }^{\circ} \mathrm{C}$. (d) 1. LiOH (aq), RT; 2. Amberlite IR-12o $\left(\mathrm{H}^{+}\right)$, RT. (e) $\mathrm{HCl}(6 \mathrm{M})$, $60{ }^{\circ} \mathrm{C}$.

Table 1. $K_{\mathrm{i}}$ values of compounds $\mathbf{3}^{-9}$ against $M t-\mathrm{SK}^{a}$

\begin{tabular}{ll} 
Compound & $K_{\mathrm{i}}(\mu \mathrm{M})$ \\
\hline 3 & $62 \pm 1$ \\
4 & $46 \pm 2$ \\
5 & $1050 \pm 17$ \\
6 & $792 \pm 16$ \\
7 & $62 \pm 1$ \\
8 & $>4000$ \\
9 & $65 \pm 1$
\end{tabular}

${ }^{a}$ Assay conditions: Tris. $\mathrm{HCl}$ (10o mM, pH 7.7), ATP (2.5 $\mathrm{mM})$, NADH (o.2 mM), PEP (1 mM), $\mathrm{MgCl}_{2}(5 \mathrm{mM})$, $\mathrm{KCl}$ (100 $\mathrm{mM}$ ), lactate dehydrogenase/pyruvate kinase ( 2.8 units), $25^{\circ} \mathrm{C} . K_{\mathrm{m}}(\mathbf{1})=544 \mu \mathrm{M}$.

Bicyclic compounds $\mathbf{3}-\mathbf{4}$ and aminoshikimic acids $\mathbf{7}$ and 9 proved to have $K_{\mathrm{i}}$ values below the $K_{\mathrm{m}}$. Saturated bicycle 4 proved to be the most potent inhibitor of the series, with a $K_{\mathrm{i}}$ of $46 \mu \mathrm{M}$. Aminoshikimic acids 7 and 9 and unsaturated bicycle 3 showed similar inhibition activities, with $K_{\mathrm{i}}$ in the range $62-65 \mu \mathrm{M}$.

In order to obtain further details of the binding mode of these inhibitors in more detail, the crystal structure of $M t$-SK in complex with one of the most potent inhibitors reported here, bicycle 3, and ADP was solved at $2.15 \AA$. The binding modes of compounds $\mathbf{4}^{-\mathbf{9}}$ with $M t$-SK were first studied using GOLD 5.0.1 ${ }^{25}$ with our previously ob- 
tained model of the Michaelis complex (see before) and they were further analyzed by MD simulation studies, which are discussed below.

\section{Binding Mode of Compounds 3-9}

Crystal structure of Mt-SK/ADP/3 ternary complex. The crystal structure of $M t$-SK with the bicycle 3 and ADP, obtained by co-crystallization, was determined at $2.15 \AA$. Crystals were cryoprotected with crystallization solution (see experimental section) supplemented with $25 \%$ glycerol and flash-frozen by rapid immersion in liquid nitrogen. X-ray diffraction data were collected from crystals cryo-cooled in a stream of cold nitrogen gas (100 K) at ambient pressure using synchrotron radiation and were subsequently processed. The crystallographic structure was solved by molecular replacement, using the structure of $M t$-SK previously described bound to shikimic acid (1) and sulfate (PDB entry $2 \mathrm{GiK})^{19}$ as a search model and the structure was refined (Figure 5). Although ATP was used in the crystallization solution, only ADP was identified in the structure, which is not surprising because ATP spontaneously hydrolyzes to ADP and phosphate. A summary of the statistics following data reduction and processing is given in Table 2 .

The $M t$-SK/ADP/3 ternary complex crystallized with three copies in the asymmetric unit (designated as chains A, B and C) (Figure 5). The three crystallographically independent copies superimpose well onto each other, with rms differences between $0.235^{-0.250} \AA$ for 152-154 superposed $C^{\alpha}$-atom pairs. ${ }^{26}$ The main differences between these chains are located in loop corresponding to residues 149-155, mainly in the position of Arg153. Comparison of $M t$-SK/ADP/3 and $M t-S K / A D P / 2$ (PDB entry $\left.{ }_{2} \mathrm{IYZ}^{16}\right)$ shows that the two structures are virtually identical (0.307 $\AA$, $0.252 \AA$ and $0.278 \AA$ A root mean square difference after superposition of 162,153 and $161 C^{\alpha}$-atom pairs from chain A, B and C, respectively) (see supporting information). The aromatic and sugar moieties of ATP are displaced by $\sim 1 \AA$ relative to their corresponding positions in PDB entry $2 \mathrm{IYZ}$ and superimpose well in $\mathrm{Mt}$ SK/ADP/1 ternary complex (PDB entry $2 \mathrm{IYQ}^{16}$ ) (see supporting information). These small differences are a consequence of variations in the position of the loop close to ATP/ADP, which is not fully resolved in PDB entry 2 IYZ. However, differences were not observed in the position of the diphosphate groups of ADP.

Unbiased, calculated, electron density maps showed clear electron density for ADP and the inhibitor molecule 3 (Figure 5a). The cyclohexene ring of inhibitor 3 occupies approximately the same site as shikimate-3-phosphate (2) or shikimic acid (1) in PDB entries $2 \mathrm{IYZ}$ and $2 \mathrm{IYQ},{ }^{16}$ respectively. As the natural substrate, the bicycle 3 binds to the active site by a salt-bridge between its carboxylate group and the guanidinium group of Arg136 along with a bidentate hydrogen bond between the carboxylate group of Asp34 and the $C_{3}$ and $C_{4}$ hydroxyl groups of the inhibitor. Moreover, the $C_{3}$ hydroxyl group interact by hydrogen bonding with the amide nitrogen of Gly8o. The ligand also interacts with the enzyme through indirect con- tacts via several bridging water molecules. Thus, the $\mathrm{C}_{4}$ hydroxyl group is anchored in the active site by interaction with Glu61, Arg58 and Gly81 by hydrogen bonding with the structural water molecule (WAT2020). The conserved Lys15 residue interacts with the $C_{3}$ hydroxyl group of 3 via a bridging water molecule (WAT20o6). Finally, two water molecules make a water bridge between the carboxylate group (WAT2041) and the oxygen atom of the $\mathrm{C}_{3}-\mathrm{C}_{5}$ ether bridge (WAT2O41 and WAT2031).
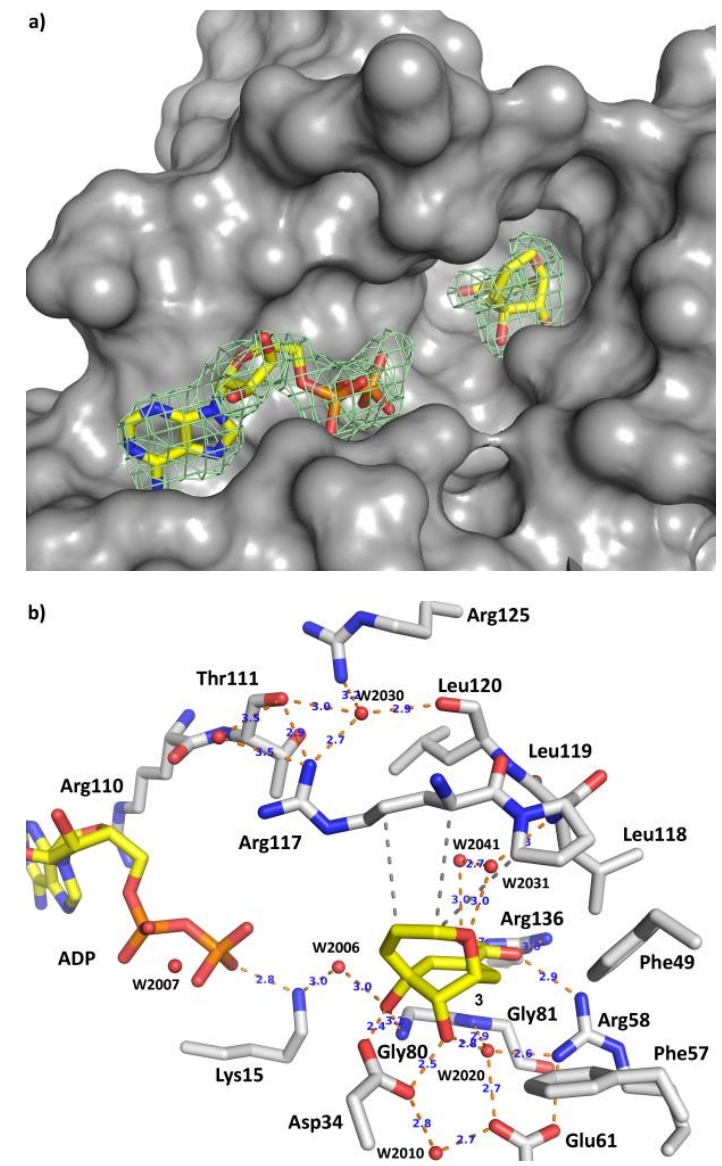

Figure 5. (a) Unbiased electron density for inhibitor 3 and ADP in ternary complex $M t-S K / A D P / 3$ (chain B). From the model obtained by molecular replacement and before inclusion of the inhibitor molecule, refinement was performed to obtain unbiased density for the inhibitor molecule and other model changes. A maximum-likelihood weighted $2 F_{\mathrm{o}}-F_{\mathrm{c}}$ map contoured at $1 \sigma$ is shown up to $1.6 \AA$ around the inhibitor molecule (green). The final model including the inhibitor molecule 3, is superimposed onto the map. (b) Interactions of inhibitor 3 with Mt-SK (grey). Polar (orange) and lipophilic (dark grey) interactions between 3 and the Mt-SK (grey) are shown. Relevant residues are shown and labeled.

Notably, the hydrogen bonding interaction of one of these water molecules (WAT2031) with the amide nitrogen of Leung, together with the lipophilic interactions of the $\mathrm{C}_{3}-\mathrm{C}_{5}$ ether bridge with the carbon side-chain of Arg117 and the carbon ring of Prol18, keep the LID closed. In fact, when the $M t$-SK/ADP/3 ternary complex was subjected to $10 \mathrm{~ns}$ of simulation in order to analyze the dynamic behavior of the latter interactions, the relative position of ligand 3, Argin and Prol18 in the active site did not change significantly. This 
finding suggests that the aforementioned interactions provide a very stable closed form of the loop.

Table 2. Crystallographic data collection and refinement statistics for the $M t$-SK complex with ADP and inhibitor $3^{a}$

\begin{tabular}{|c|c|}
\hline Data processing $^{\mathrm{a}}$ & Mt-SK/ADP/3 \\
\hline space group & $P \mathbf{2}_{1}$ \\
\hline cell parameters (a, b, c), $\AA$ & $\begin{array}{l}40.65,60.96,89.98(\beta= \\
\left.95.44^{\circ}\right)\end{array}$ \\
\hline wavelength $(\AA)$ & 0.9798 \\
\hline detector & Dectris Pilatus3 6M \\
\hline observed reflections $^{b}$ & $75346(8274)^{c}$ \\
\hline resolution range $(\AA)$ & $28.85^{-2.15}(2.27-2.15)$ \\
\hline Wilson B $\left(\AA^{2}\right)$ & 21.0 \\
\hline multiplicity & $3 \cdot 3(3.0)$ \\
\hline completeness & $0.956(0.794)$ \\
\hline$R_{\text {merge }}$ & $0.083(0.344)$ \\
\hline \multicolumn{2}{|l|}{ Refinement $^{\mathrm{d}}$} \\
\hline resolution range $(\AA)$ & $28.87-2.15(2.27-2.15)$ \\
\hline $\begin{array}{l}\text { reflections used in refine- } \\
\text { ment }^{c}\end{array}$ & $21698(2625)$ \\
\hline reflections used for $R_{\text {free }}$ & $1165(138)$ \\
\hline$R$ factor ${ }^{\mathrm{e}}$ & $0.172(0.231)$ \\
\hline$R_{\text {free }}^{\text {f }}$ & $0.235(0.316)$ \\
\hline $\begin{array}{l}\text { rmsd } \\
(\text { deg }))\end{array} \quad$ (bonds $\quad(\AA ̊) /$ angles & $0.014 / 1.7$ \\
\hline
\end{tabular}

Final Model

Protein/inhibitor/ADP/water 3774/45/81/141 atoms

average B pro- $30.4 / 25 \cdot 3 / 40.2 / 39.4$

tein/inhibitor/ADP/water

$\left(\AA^{2}\right)$

Ramachandran statistics $^{g}(\%) \quad$ 98.o/100.0

PDB accession code $\quad 4 B Q S$

${ }^{a}$ Results from SCALA. ${ }^{27}{ }^{b}$ No sigma cut-off or other restrictions were used for inclusion of reflections. 'Values in parentheses are for the highest resolution bin, where applicable. ${ }^{d}$ Results from REFMAC. ${ }^{28}{ }^{e} R$-factor $=$ $\Sigma|| F_{0} b s(h k l)|-| F_{c} a l c(h k l)|| / \Sigma\left|F_{0} b s(h k l)\right| .{ }^{f}$ According to Brünger. ${ }^{29}$ According to the program MOLPROBITY. ${ }^{30}$ The percentages indicated are for residues in favored and total allowed regions, respectively.

Saturated Bicycle 4. Docking and MD simulation studies showed that, in general, the two bicyclic derivatives 3 and 4 should have a similar binding mode. The main differences that would arise from the reduction of the double bond of the $C_{3}-C_{5}$ ether bridge in 3 are more lipophilic interactions of the ether bridge with the conserved residues Arg117 and Pro118 (Figure 6a). The change in hybridation would mean that the $\mathrm{C}_{3}-\mathrm{C}_{5}$ bridge would be located closer to the carbon side chain of conserved
Arg117 and the carbon ring of conserved Pro118. As a consequence, the flexibility of the LID domain would be further reduced in comparison with that in the unsaturated bicycle 3. In addition, a very effective closure of the SB domain seems to take place. Both effects would reduce the flexibility of the two domains and this might explain its higher inhibitory potency.

3-Aminoshikimic acids 7 and $\mathbf{9}$. The studies carried out on $(3 R)-(7)$ and $(3 S)-3$-aminoshikimic acids (9) showed that in both cases the cyclohexene ring would bind in a similar way to the natural substrate, even in the case of ligand 9, which has the opposite stereochemistry at $C_{3}$ (Figures $6 \mathrm{~b}-\mathrm{c})$. This is because both $\mathrm{C}_{3}$ amino groups would interact with the $\gamma$-phosphate of ATP through a strong electrostatic interaction. In both cases, the $\gamma$-phosphate of ATP and the amino group remain very close during the 10 ns of simulation (3.0-3.5 $\AA$ between heavy atoms) and in general, both ternary complexes proved to be very stable as significant changes were not observed. This electrostatic interaction favors that the nucleotide and SB domains remain very close. In fact, the hydrogen bond between the side-chains of Ser16 and Asp32 residues is maintained $\sim 1.5^{-1.7} \AA$ during the simulation. As a consequence, the flexibility of the LID and the SB domains is dramatically reduced. Notably, in the case of 3epiaminoshikimic acid (9) the active site is even more closed than that in the natural substrate and its epimer 7 .

Unlike (3R)-3-aminoshikimic acid (7), 3-epiaminoshikimic acid (9) lacks the possible hydrogenbonding interaction with the side-chain of conserved Asp34 and the water network would be displaced by about $1-1.5 \AA$ from the $C_{1}$ carboxylate group and the $C_{5}$ hydroxyl group as a result of the axial arrangement of the amino group. Despite this, the $C_{5}$ hydroxyl group would remain axially fixed through a strong intramolecular hydrogen-bonding interaction with the $C_{3}$ amino group. It seems that the overall binding interactions of both aminoshikimic acids are quite similar and the interaction with the $\gamma$-phosphate of ATP seems to be crucial in freezing their binding to the active site, a situation that may explain their similar inhibitory potencies.

Hydroxyshikimic acid 6. The MD simulation studies carried out with (6R)-6-hydroxyshikimic acid (6) showed that replacement of the pro- $R$ hydrogen in $\mathbf{1}$ by a hydroxyl group caused significant changes in the water network and in the recognition of the $\mathrm{C}_{1}$ carboxylate group (Figure $6 \mathrm{~d})$. As a consequence, the ligand caused large movements in the $\alpha$-helices $\alpha_{2}$ and $\alpha_{3}$ of the SB domain.

Thus, an opening of the SB domain by nearly $6 \AA$ is observed (see supporting information). With the opening of the SB domain, the ligand would undergo a conformational change to the thermodynamically more stable conformation, i.e. with $\mathrm{C}_{4}$ and $\mathrm{C}_{5}$ hydroxyl groups in the pseudo-equatorial conformation. This binding conformation of $\mathbf{6}$ and the greater flexibility of the SB domain might be responsible for the lower inhibitory potency of this compound. 

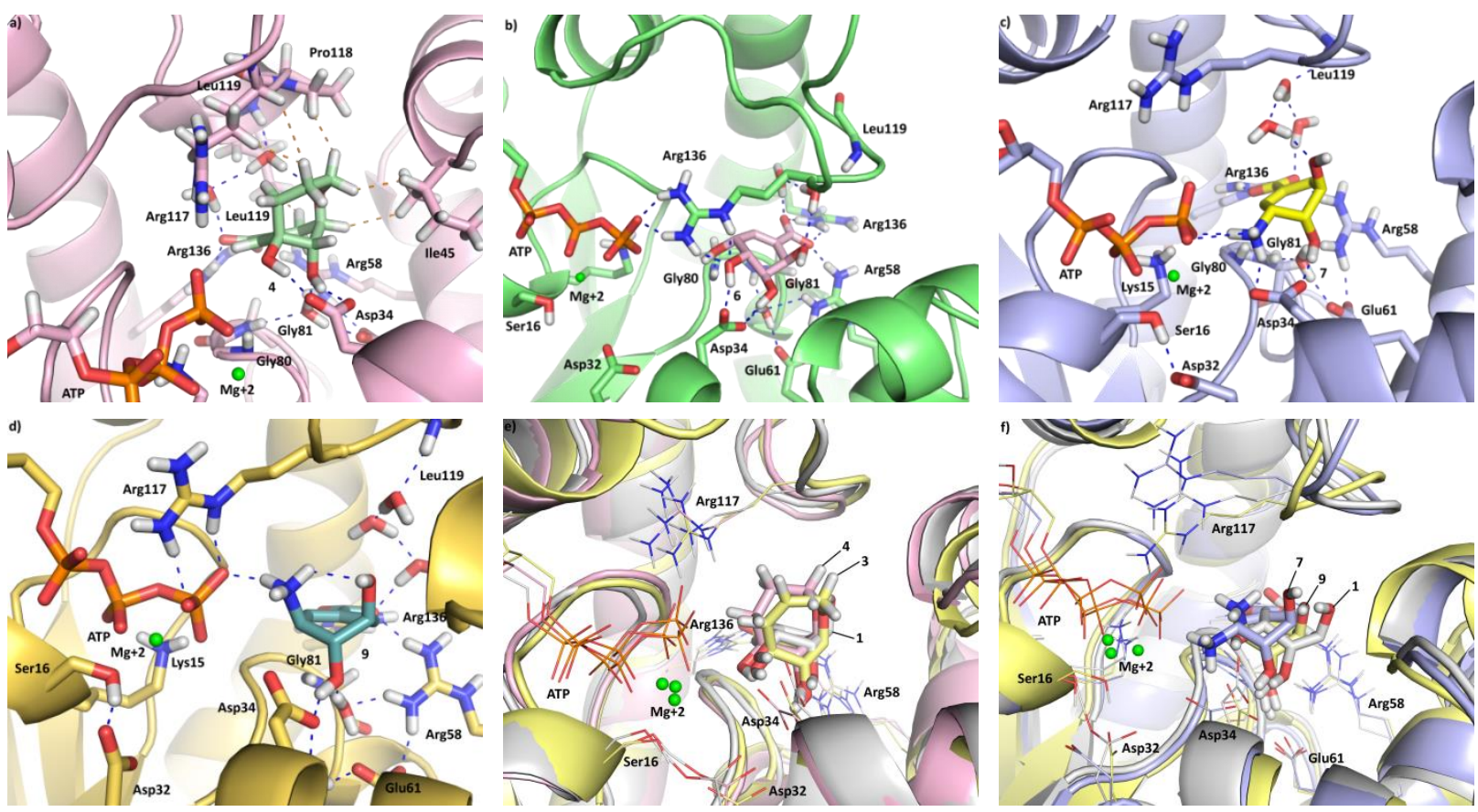

Figure 6. Binding mode of bicycle (4, a), (6R)-6-hydroxyshikimic acid (6, b), (3R)-3-aminoshikimic acid (7, c) and (3S)-3aminoshikimic acid (9, d) obtained by MD simulation studies. Comparison of the binding mode of bicycles 3 and 4 and $3^{-}$ aminoshikimic acids $\mathbf{7}$ and $\mathbf{9}$ with the natural substrate are shown in figures e and f, respectively. Relevant side chain residues are shown and labeled. Polar (blue) and lipophilic (orange) interactions between ligands and the $M t$-SK are shown.

The results suggest that the axial incorporation of a hydroxyl group at $\mathrm{C} 6$ of $\mathbf{1}$ and, in general, a group able to form a hydrogen bond might not increase the binding affinity because it does not favor a closed form of the SB domain. Similar behavior was observed with ligand 5.

The binding free energies of the ligands were calculated using MM/PBSA ${ }^{31}$ approach in explicit water (GB) as implemented in Amber. The results suggested that 3aminoshikimic acids 7 and 9 and the bicyclic derivatives 3 and 4 have higher affinity for the enzyme than the natural substrate, as it was found experimentally. Further functionalization of the reported inhibitors is required to improve their inhibition potency. The incorporation of additional functional groups into the core structure of bicyclic compounds 3-4 and 3-aminoshikimic acids 7 and 9 should provide extra binding interactions with the active site and therefore lower inhibition constants. Such modifications are undertaken in our laboratories.

\section{CONCLUSIONS AND FINAL REMARKS}

The key interactions of substrate binding and the enzyme movements that are essential for catalytic turnover of shikimate kinase from $M$. tuberculosis have been investigated by structural and computational studies. MD simulation studies carried out with the enzyme/substrate complex revealed the key binding interactions and the movements of the SB and LID domains for recognition of the unfavorable conformation of shikimic acid (1) and showed that this conformation enables a selective phosphorylation of the $C_{3}$ hydroxyl group in $\mathbf{1}$. The study of the dynamic behavior of the enzyme/product complex allowed us to identify the key residues and domain movements responsible for the release of shikimate-3phosphate (2) from the active site. Thus, shikimate-3phosphate (2) is expelled from the active site by three arginine residues (Arg117, Arg136 and Arg58), which unveiled a previously unknown key role of these conserved residues. Arg117 triggers the process by forming a strong electrostatic interaction with the $\mathrm{C}_{3}$ phosphate group in 2. The latter interaction causes destabilization of the product in the active center and a conformational change of the product occurs, which in turn leads a large opening of the SB domain. The inhibition of this enzyme was investigated with conformationally restricted shikimic acid analogs 3-4, aminoshikimic acids 7 and 9 and hydroxy derivatives $\mathbf{5}$ and $\mathbf{6}$. All of the compounds proved to be competitive reversible inhibitors of the enzyme. Saturated bicycle 4 proved to be the most potent inhibitor of the series, with a $K_{\mathrm{i}}$ of $46 \mu \mathrm{M}$. Aminoshikimic acids 7 and 9 and unsaturated bicycle 3 showed a similar inhibition activity, with $K_{\mathrm{i}}$ values in the range $62-65 \mu \mathrm{M}$.

The crystal structure of the enzyme in complex with ADP and one of the most potent inhibitors, bicycle 3, was solved at $2.15 \AA$. The crystal structure and the MD simulation studies reported here show that the lipophilic interactions of the $C_{3}-C_{5}$ ether bridge in 3 with the carbon side-chain of Arg117 and the carbon ring of Pron18 are key factors in reducing the flexibility of the LID domain. In addition, the conformational rigidity provided by the $\mathrm{C}_{3}$ $\mathrm{C}_{5}$ bridge allows the ligand to be anchored to the active 
site and keeps the SB domain close to the ligand. The reduction of the double bond of the $\mathrm{C}_{3}-\mathrm{C}_{5}$ ether bridge in 3 enhances both effects and this might explain the higher inhibition potency of saturated bicycle 4 .

The replacement of the $C_{3}$ hydroxyl group in the natural substrate by an amino group also proved to be a promising strategy to inhibit the enzyme. Regardless of the configuration of the $C_{3}$ center, both amino groups interact with the $\gamma$-phosphate of ATP by strong electrostatic interactions that seem to be crucial in freezing their binding to the active site. As a consequence, the flexibility of the LID and the SB domains is dramatically reduced. By contrast, the incorporation of a hydroxyl group at C6 in $\mathbf{1}$ favors large movements of the SB domain and this allows a conformational change of the ligand to the thermodynamic conformer, which is not recognized by the enzyme. The results described here show that, since the SK enzyme is wonderfully designed to recognize a thermodynamically less stable conformation of the natural substrate, those compounds capable of maintaining the conformation recognized by the enzyme and also causing a reduction in the mobility of the LID and/or SB domains, represent a good strategy for the development of enzyme inhibitors. Although virtual screening studies suggested several molecules as potential inhibitors of the $M t$-SK enzyme, ${ }^{32}$ to our knowledge the compounds described here are the first inhibitors developed against $M t$-SK. The results presented here improve our understanding of some of the determinants of binding affinity and product release and provide guides for the next high-affinity generation of inhibitors of the SK enzyme, which is an attractive target for the development of new drugs against several important bacterial diseases.

\section{EXPERIMENTAL SECTION}

Molecular dynamics simulations. Ligand minimization. Ligand geometries were minimized using a restricted Hartree-Fock (RHF) method and a 6-31G(d) basis set, as implemented in the $a b$ initio program Gaussian $09 .^{33}$ The resulting wavefunctions were used to calculate electrostatic potential-derived (ESP) charges employing the restrained electrostatic potential (RESP) ${ }^{34}$ methodology, as implemented in the assisted model building with energy refinement (AMBER) ${ }^{35}$ suite of programs. The missing bonded and non-bonded parameters were assigned, by analogy or through interpolation, from those already present in the AMBER database (GAFF). ${ }^{33,36}$

Generation and minimization of ternary complexes. Simulations were carried out using the enzyme geometries found in the crystal structures of Mt-SK in complex with shikimic acid (1) and ADP (PDB code $2 \mathrm{IYQ}^{16}$ ) and shikimate-3-phosphate (2) and ADP (PDB code $2 \mathrm{IYZ}^{16}$ ). The first one was used for the Michaelis complex and the latter one for the products complex. The coordinates of the unsolved residue $\mathrm{Arg}_{152}$ in PDB code $2 \mathrm{IYZ}$ were incorporated from PDB code 2IYQ. ATP and $\mathrm{Mg}^{2+}$ were manually docked into the active site after superposition with PDB code $2 \mathrm{IYW}^{16}$. Crystallographic water molecules were maintained in both complexes except for those coordi- nated with the $\beta$-phosphate of ADP in PDB 2IYQ. For the Michaelis complex, the crystallographic water molecules coordinated with the $\gamma$-phosphate of ATP and $\mathrm{Mg}^{2+}$ in PDB 2 IYW were also added. Protein $N$ - and $C$-terminal groups were modified as $\mathrm{N}$-acetyl and $\mathrm{N}$-methyl amide derivatives, respectively. Computation of the protonation state of titratable groups at $\mathrm{pH}$ 7.0 were carried out using the $\mathrm{H}^{++}$Web server. ${ }^{37}$ Addition of hydrogen and molecular mechanics parameters from the ffo 3 and GAFF force fields, respectively, were assigned to the protein and the ligands using the LEaP module of AMBER 10.0..$^{35-36,38}$ ATP, ADP and $\mathrm{Mg}^{2+}$ parameters used with the AMBER force field were included. ${ }^{39,18}$ All terminal hydrogens were first minimized in vacuo (2000 steps, half of them steepest descent, the other half conjugate gradient). For the products/enzyme complex, sequence DTNRRNP, in which missing Arg152 was introduced, was previously minimized in vacuo (200o steps, half of them steepest descent, the other half conjugate gradient) to eliminate potential tensions generated. Energy minimization using the implicit solvent GB model was then carried out in stages, starting with ligand (10oo steps, half of them steepest descent, the other half conjugate gradient), protein side chains (1000 steps, idem) and finally the entire complex (100o steps, idem). A positional restraint force constant of $50 \mathrm{kcal} \mathrm{mol}^{-1} \AA^{-2}$ was applied to those unminimized atoms in each step during all calculations. The complex was neutralized by addition of chloride ions and immersed in a truncated octahedron of $\sim 5300 \mathrm{TIP} 3 \mathrm{P}$ water molecules..$^{35,40,41}$

Simulations. MD simulations were performed using the sander module from the AMBER 10.o or 11.o suite of programs. Periodic boundary conditions were applied and electrostatic interactions were treated using the smooth particle mesh Ewald method (PME) ${ }^{42}$ with a grid spacing of $1 \AA$ A. The cutoff distance for the non-bonded interactions was $9 \AA$ A. The SHAKE algorithm ${ }^{43}$ was applied to all bonds containing hydrogen, using a tolerance of $10^{-5} \AA$ and an integration step of 2.0 fs. Minimization was carried out in three steps, starting with the octahedron water hydrogens, followed by solvent molecules and sodium counterions and finally the entire system. The minimized system was heated at $300 \mathrm{~K}(1 \mathrm{~atm}, 25 \mathrm{ps}$, a positional restraint force constant of $50 \mathrm{kcal} \mathrm{mol}^{-1} \AA^{-2}$ ). These initial harmonic restraints were gradually reduced to $5 \mathrm{kcal} \mathrm{mol}^{-}$ ${ }^{1} \AA^{-2}$ (10 steps) and the resulting systems were allowed to equilibrate further. Unrestrained MD simulations were carried out for 10 ns (500 steps). System coordinates were collected every 2 ps for further analysis. A slow-cooling MD simulation with constraints of $5 \mathrm{Kcal} \mathrm{mol}^{-1} \AA^{-2}$ was performed (6 steps until $273 \mathrm{~K}$ ). Finally, minimization of the entire complexes was performed with constraints of 5 Kcal mol ${ }^{-1} \AA^{-2}$.

Crystallization and structure determination of the Mt-SK/ADP/3 ternary complex. A solution of freshly purified $M t$-SK $\left(1.5 \mathrm{mg} \mathrm{mL}^{-1}\right)^{14}$ was concentrated to $14 \mathrm{mg}$ $\mathrm{mL}^{-1}$ in $20 \mathrm{mM}$ Tris. $\mathrm{HCl} \mathrm{pH} 7.4,40 \mathrm{mM} \mathrm{KCl}$ and $0.1 \%$ sodium azide. Crystallization was carried out with concentrated protein solution, $5 \mathrm{mM}$ ATP and $0.25 \mathrm{M}$ of 
compound 3. ATP and compound 3 were added to aliquots of the concentrated protein solution to give solutions of approximately 7 and 20 equivalents of ATP and inhibitor per protein monomer, respectively. Prismshaped crystals of up to $0.10 \mathrm{~mm} \times 0.02 \mathrm{~mm} \times 0.02 \mathrm{~mm}$ were obtained in sitting drops after three months of vapor diffusion against $0.15 \mathrm{~mL}$ reservoirs containing $20 \%$ (w/v) poly(ethyleneglycol) 3350, 0.5 M LiCl and $100 \mathrm{mM}$ Tris. $\mathrm{HCl} \mathrm{pH}$ 7.8. Drops contained $2.0 \mu \mathrm{L}$ of protein/ATP/inhibitor solution mixed with $2.0 \mu \mathrm{L}$ of reservoir solution.

Crystals were harvested in reservoir solution supplemented with $25 \%(\mathrm{w} / \mathrm{v})$ glycerol, mounted into a cryoloop and flash-frozen by rapid immersion in liquid nitrogen. X-ray diffraction data were collected on beamline Io2 (Synchrotron Diamond, Oxfordshire, UK) from crystals maintained at $100 \mathrm{~K}$. The data were processed, scaled and analyzed using XDS, ${ }^{44}$ SCALA $^{27}$ and other programs within the $\mathrm{CCP}_{4}$ software suite. ${ }^{45}$ The structure of $M t$ SK/ADP/3 ternary complex was solved by molecular replacement using the program MOLREP ${ }^{46}$ with a search model generated from PDB entry $2 \mathrm{GlK}^{19}$ from which ligands and solvent were removed. The structure and geometrical restraints of the inhibitor were generated with the PRODRG2 server ${ }^{47}$. Ligands were manually placed during the model building, which was performed with COOT. ${ }^{47}$ Reflections for the calculation of Rfree $^{29}$ were selected randomly. Refinement of the model was performed with REFMAC ${ }^{28}$ and final structure validation was performed with MOLPROBITY..$^{30}$ Data collection, refinement and model statistics are summarized in Table 2.

\section{ASSOCIATED CONTENT}

\section{Supporting Information}

Experimental procedures for the synthesis and characterization of compound 3-9, shikimate kinase assay and extra figures of the MD simulation and structural studies. Copies of ${ }^{1} \mathrm{H}$ NMR, ${ }^{13} \mathrm{C}$ NMR and DEPT spectra and Dixon plots for compounds $3^{-9}$ are also included. This material is available free of charge via the Internet at http://pubs.acs.org.

\section{Accession Codes}

Coordinates and structure factors are available from the Protein Data Bank with accession code 4 BQS.

\section{AUTHOR INFORMATION}

\section{Corresponding Author}

*Prof. Dr. Concepción González-Bello, Centro Singular de Investigación en Química Biológica y Materiales Moleculares (CIQUS), Universidad de Santiago de Compostela, calle Jenaro de la Fuente s/n, 15782 Santiago de Compostela, Spain. Tel: +34 881815726; FAX: +34 881815704; e-mail: concepcion.gonzalez.bello@usc.es

\section{Notes}

The authors declare no competing financial interest.

\section{ACKNOWLEDGMENT}

Financial support from the Spanish Ministry of Economy and Competitiveness (SAF2010-15076 to CGB and BFU2011-24843 to MJvR) and the Xunta de Galicia (10PXIB2200122PR and
GRC2010/12) is gratefully acknowledged. BB thanks the Spanish Ministry of Education for her FPU fellowship. VP and CGD thank the Spanish Ministry of Economy and Competitiveness for their respective FPI fellowships. JMO thanks the Xunta de Galicia for a Plan I2C postdoctoral fellowship. Diamond Light Source, and James Sandy in particular, is acknowledged for providing the excellent synchrotron radiation facilities of beamline Ioz. We are also grateful to the Centro de Supercomputación de Galicia (CESGA) for use of the Finis Terrae computer. ${ }^{\ddagger}$ In memory of Prof. Enrique Pérez-Payá.

\section{ABBREVIATIONS}

SK, Shikimate kinase; $M t$-SK, Shikimate kinase from Mycobacterium tuberculosis; TB, tuberculosis; MD, molecular dynamics; SB, substrate binding; PDB, protein data bank. GB, generalized Born.

\section{REFERENCES}

(1) Walsh, C. Antibiotics: Actions, Origins, Resistance, ASM Press, Washington, DC, 2003.

(2) (a) Fischbach, M. A.; Walsh, C. T. Science 2009, 325, 1089-1093. (b) Lewis, K. Nat. Rev. Drug Discovery 2013 12, 371-387. (c) Busch, K. et al. Nature Rev. Microbiol. 2011, 9, 894-896. (d) Hurdle, J. G.; O'Neil, A. J.; Chopra, I.; Lee, R. E. Nature Rev. Microbiol. 2011, 9, 62-7.4. (e) Clatworthy, A. E.; Pierson, E.; Hung, D. T. Nature Chem. Biol. 2007, 3, 541-548.

(3) (a) Haslam, E. The Shikimate Pathway, Wiley, New York, 1974. (b) Abell, C. Enzymology and molecular biology of the shikimate pathway, in Comprehensive Natural Products Chemistry (Ed.: U. Sankawa), Elsevier Science Ltd., Oxford, 1999, pp. 573-607. (c) Bentley, R. Crit. Rev. Biochem. Mol. Biol. 1990, 25, 307-383. (d) Herrmann, K.; Weaver, L. Annu. Rev. Plant Physiol. Plant Mol. Biol. 1999, 50, 473-755.

(4) (a) Roberts, F.; Roberts, C. W.; Johnson, J. J.; Kyle, D. E.; Krell, T.; Coggins, J. R.; Coombs, G. H.; Milhous, W. K.; Tzipori, S.; Ferguson, D. J. P.; Chakrabarti, D.; McLeod, R. Nature 1998, 393, 801-805. (b) Keeling, P. J.; Palmer, J. D.; Donald, R. G.; Roos, D. S.; Waller, R. F.; McFadden, G. I. Nature 1999, 397, 219-220. (c) Campbell, S. A.; Richards, T.A.; Mui, E. J.; Samuel, B. U.; Coggins, J. R.; McLeod, R.; Roberts, C. W. Int. J. Parasit. 2oo4, 34, 5-13. (d) Roberts, C. W.; Roberts, F.; Lyons, R. E.; Kirisits, M. J.; Mui, E. J.; Finnerty, J.; Johnson, J. J.; Ferguson, D. J.; Coggins, J. R.; Krell, T.; Coombs, G. H.; Milhous, W. K.; Kyle, D. E.; Tzipori, S.; Barnwell, J.; Dame, J. B.; Carlton, J.; McLeod, R. J. Infect. Dis. 2oo2, 185 (suppl 1), S25-S36.

(5) (a) Salama, N. R.; Shepherd, B.; Falkow, S. J. Bacteriol. 2004, 186, 7926-7935. (b) Sassetti, C. M.; Boyd, D. H.; Rubin, E. J. Mol. Microb. 2003, 48, 77-84. (c) de Berardinis, V.; Vallenet, D.; Castelli, V.; Besnard, B.; Pinet, A.; Cruaud, C.; Samair, S.; Lechaplais, C.; Gyapay, G.; Richez, C.; Durot, M.; Kreimeyer, A.; Le Fèvre, F.; Schächter, V.; Pezo, V.; Döring, V.; Scarpelli, C.; Médigue, C.; Cohen, G. N.; Marlière, P.; Salanoubat, M.; Weissenbach, J. Mol. Syst. Biol. 2008, 4, 1-15.

(6) (a) Steinrücken, H. C.; Amhrein, N. Biochem. Biophys. Res. Commun. 1980, 94, 1207-1212. (b) Franz, J. E.; Mao, M. K.; Sikorski, J. A. Glyphosate: a unique global herbicide. Washington, DC: American Chemical Society Monograph 189; American Chemical Society; 1997. (c) Sikorski, J. A.; Gruys, K. J. Acc. Chem. Res. 1997, 30, 2-8. (d) 
Franz, J. E. The herbicide glyphosate. Grossbard, E. \& Atkinson, D., Eds. Boston, MA: Butterworths; 1985. pp 3-17. (e) Steinrücken, H. C.; Amhrein, N. Eur. J. Biochem. 1984, 143, 351-357.

(7) (a) Schönbrunn, E.; Eschenburg, S.; Shuttleworth, W. A.; Schloss, J. V.; Amrhein, N.; Evans, J. N. S.; Kabsch, W. PNAS 2001, 98, 1376-1380. (b) Funke, T.; Han, H.; HealyFried, M. L.; Fischer, M.; Schönbrunn, E. PNAS 2006, 103, 13010-13015.

(8) De María, N.; Becerril, J. M.; García-Plazaola, J. I.; Hernández, A.; De Felipe, M. R.; Fernández-Pascual, M. J. Agric. Food Chem. 2006, 54, 2621-2628.

(9) Chen, K.; Dou, J.; Tang, S.; Yang, Y.; Wang, H.; Fang, H.; Zhou, C. Bioresource Technology 2012, 119, 141-147.

(10) (a) Data base for essential genes in bacteria see www.essentialgene.org. (b) Zhang, R.; Ou, H.-Y.; Zhang, C.-T. DEG, a database of essential genes. Nucleic Acids Res. 2004, 32, D271-D272. (c) Zhang, R.; Lin, Y. DEG 5.0, a database of essential genes in both prokaryotes and eukaryotes. Nucleic Acids Res. 2009, 37, D455-D458.

(11) http://www.who.int/tb/research/en/

(12) (a) Espinal, M. A. Tuberculosis 2003, 83, 44-51. (b) Dye, C.; Williams, B. G. Science 2010, 328, 856-861.

(13) Krell, T.; Maclean, J.; Boam, D. J.; Cooper, A.; Resmini, M.; Brocklehurst, K.; Kelly, S. M.; Price, N. C.; Lapthorn, A. J.; Coggins, J. R. Protein Science 2001, 10, 1137-1149.

(14) Dhaliwal, B.; Nichols, C. E.; Ren, J.; Lockyer, M.; Charles, I.; Hawkins, A. R.; Stammers, D. K. FEBS Lett. 2004, 574, 49-54.

(15) Gu, Y.; Reshentnikova, L.; li, Y.; Wu, Y.; Yan, H.; Singh, S.; Ji, X. J. Mol. Biol. 2002, 319, 779-789.

(16) Hartmann, M. D.; Bourenkov, G. P.; Oberschall, A.; Strizhov, N.; Bartunik, H. D. J. Mol. Biol. 2006, 364, 411-423.

(17) DeLano, W.L. The PyMOL Molecular Graphics System. (2008) DeLano Scientific LLC, Palo Alto, CA, USA. http://www.pymol.org/

(18) ATP and ADP parameters used with the AMBER force field were downloaded from http://www.pharmacy.manchester.ac.uk/bryce/amber/.

Meagher, K. L.; Redman, L. T.; Carlson, H. A. Development of polyphosphate parameters for use with the AMBER force field. J. Comput. Chem. 2003, 24, 1016-1025.

(19) Gan, J.; Gu, Y.; Li, Y.; Yan, H.; Ji, X. Biochemistry 20o6, 45, 8539-8545.

(20) Alves, C.; Barros, M. T.; Maycock, C. D.; Ventura, M. R. Tetrahedron 1999, 55, 8843-8856.

(21) Hudlicky, T.; Price, J. D.; Rulin, F.; Tsunoda, T. J. Am. Chem. Soc. 1990, 112, 9439-9440.

(22) (a) Shie, J.-J.; Fang, J.-M.; Wong, C.-H. Angew. Chem. Int. Ed. 2008, 47, 5788-5791. (b) Blacker, A. J.; Booth, R. J.; Davies, G. M.; Sutherland, J. K. J. Chem. Soc. Perkin Trans. 1 1995, 2861-2870.

(23) (a) Song, C.; Jiang, S.; Singh, G. Tetrahedron Lett. 2oo1, 42, 9069-9071. (b) Sutherland, J. K.; Whitehead, R. C.; Davies, G. M. J. Chem. Soc., Chem. Commun. 1933, 464465. (c) Trao, C. H.; Crout, D. H. G.; Errington, W. Tetrahedron: Asymmetry 1996, 7, 691-698.

(24) Adams, H.; Bailey, N. A.; Brettle, R.; Cross, R.; Frederickson, M.; Haslam, E.; MacBeath, F. S.; Davies, G. M. Tetrahedron 1996, 52, 8565-8580.

(25) http://www.ccdc.cam.ac.uk/products/life sciencies/gold $L$

(26) rms differences of $0.250 \AA$ for 154 superposed $C^{\alpha}$-atom pairs when chain $\mathrm{A}$ is superimposed onto $\mathrm{B}, 0.235 \AA$ for 152 superposed $C^{\alpha}$-atom pairs when chain $A$ is superim- posed onto $C$ and $0.248 \AA$ for 154 superposed $C^{\alpha}$-atom pairs when chain $B$ is superimposed onto $C$.

(27) Evans, P. Acta Crystallogr. 2oo6, D62, 72-82.

(28) Murshudov, G. N.; Vagin, A. A.; Dodson, E. J. Acta Crystallogr. D Biol. Crystallogr. 1997, 53, 240-255.

(29) Brünger, A. T. Methods Enzymol. 1997, 277, 366-396.

(30) Davis, I. W.; Leaver-Fay, A.; Chen, V. B.; Block, J. N.; Kapral, G. J.; Wang, X.; Murray, L. W.; Arendall, W. B. $3^{\text {rd }}$; Snoeyink, J.; Richardson, J. S.; Richardson, D. C. Nucl. Acids Res. 2007, 35, W375-W383.

(31) Miller III, B. R., McGee Jr., T. D., Swails, J. M. Homeyer, N. Gohlke, H. and Roitberg, A. E. J. Chem. Theory Comput. 2012, 8, 3314-3321.

(32) (a) Segura-Cabrera, A.; Rodríguez-Pérez, M. A. Bioorg. Med. Chem. Lett. 20o8, 18, 3152-3157. (b) Kumar, M.; Verma, S.; Sharma, S.; Srinivasan, A.; Singh, T. P.; Kaur, P. Chem. Biol. Drug. Res. 2010, 76, 277-284. (c) Vianna, C. P.; Azevedo Jr., W. F. J. Mol. Model 2012, 18, 755-764.

(33) Gaussian 09, Revision A.2, Frisch, M. J. et al. Gaussian, Inc., Wallingford CT, 2009.

(34) (a) Cornell, W. D.; Cieplak, P.; Bayly, C. I.; Gould, I. R.; Merz, K. M.; Ferguson, D. M.; Spellmeyer, D. C.; Fox, T.; Caldwell, J. W.; Kollman, P. A. J. Am. Chem. Soc. 1995, 117, 5179-5197. (b) $\quad$ http://q4mdforcedfieldtools.org/RED/resp/

(35) Case, D. A.; Cheatham, T. E.; Darden, T.; Gohlke, H.; Luo, R.; Merz, K. M.; Onufriev, O.; Simmerling, C.; Wang, B.; Woods, R. J. J. Comput. Chem. 2005, 26, 16681688.

(36) (a) Wang, J.; Wolf, R. M.; Caldwell, J. W.; Kollman, P. A.; Case, D. A. J. Comp. Chem. 2oo4, 25, 1157-1174. (b) Wang, J.; Wang, W.; Kollman, P. A.; Case, D. A. J. Mol. Graph. Mod. 2006, 25, 247-26o.

(37) (a) Gordon, J. C.; Myers, J. B.; Folta, T.; Shoja, V.; Heath, L. S.; Onufriev, A. Nucleic Acids Res 2005, 33 (Web Server issue):W368-371. (b) http://biophysics.cs.vt.edu/H++.

(38) Amber Tools 1.5: Case, D. A.; Darden, T. A.; Cheatham III, T. E.; Simmerling, C. L.; Wang, J.; Duke, R. E.; Luo, R.; Walker, R. C.; Zhang, W.; Merz, K. M.; Roberts, B.; Wang, B.; Hayik, S.; Roitberg, A.; Seabra, G.; Kolossvai, I.; Wong, K.F.; Paesani, F.; Vanicek, J.; Liu, J.; Wu, X.; Brozell, S. R.; Steinbrecher, T.; Gohlke, H.; Cai, Q.; Ye, X.; Wang, J.; Hsieh, M.-J.; Cui, G.; Roe, D. R.; Mathews, D. H.; Seetin, M. G.; Sagui, C.; Babin, V.; Luchko, T.; Gusarov, S.; Kovalenko, A.; Kollman, P. A. AMBER 11, University of California, San Francisco, 2010.

(39) $\mathrm{Mg}^{2+}$ parameters used with the AMBER force field were downloaded from http://www.pharmacy.manchester.ac.uk/bryce/amber/. Allnér, O.; Nilsson, L.; Villa, A. J. Chem. Theory Comput. 2012, 8, 1493-1502.

(40) Aqvist, J. J. Phys. Chem. 1990, 94, 8021-8024.

(41) Jorgensen, W. L.; Chandrasekhar, J.; Madura, J. D. J. Chem. Phys. 1983, 79, 926-935.

(42) Darden, T. A.; York, D.; Pedersen, L. G. J. Chem. Phys. 1993, 98, 10089-10092.

(43) Ryckaert, J.-P.; Ciccotti, G.; Berendsen, H. J. C. J. Comput. Phys. 1977, 23, 327-341.

(44) Kabsch, W. Acta Cryst. 2010, D66, 125-132.

(45) Winn, M. D. J. Synchrotron Radiat. 2003, 10, 23-25.

(46) Vagin, A.; Teplyakov, A. J. Appl. Cryst. 1997, 30, 1022-1025.

(47) Schüttelkopf, A. W.; van Aalten, D. M. F. Acta Crystallogr. 2004, D6o, 1355-1363.

(48) Emsley, P.; Cowtan, K. Acta Crystallogr. 2004, D6o, 21262132. 
Mycobacterium tuberculosis Shikimate Kinase Inhibitors: Design and Simulation Studies of the Catalytic Turnover

Beatriz Blanco, Verónica Prado, Emilio Lence, José M. Otero, Carmela Garcia-Doval, Mark J. van Raaij, Antonio L. Llamas-Saiz, Heather Lamb, Alastair R. Hawkins, and Concepción GonzálezBello*
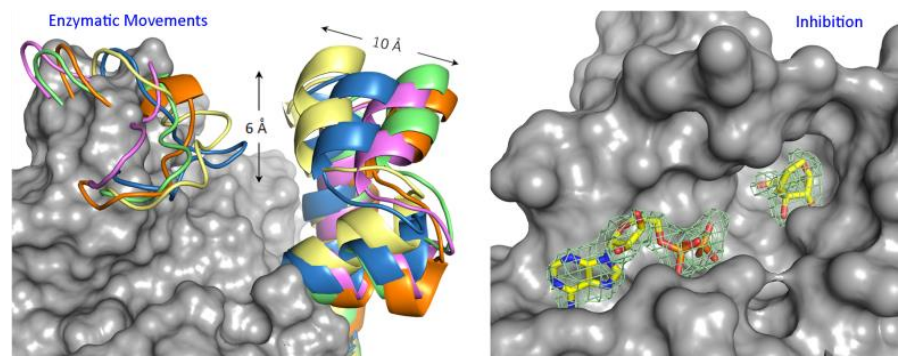